\title{
Screening for Depression among Schizophrenia Patients: A Cross-sectional Study
}

\author{
Nabil Al-Ruwais ${ }^{1}$, Yassir AlHarbi ${ }^{2}$, Bandar Abalkhail ${ }^{3}$, Yassir Ibrahim ${ }^{4}$, Waleed Abounaem ${ }^{5}$, Seham Heweidy ${ }^{6}$, Rafaat Ahmaed ${ }^{7}$, \\ Nevin FW Zaki ${ }^{8}$, John Zaki ${ }^{9}$
}

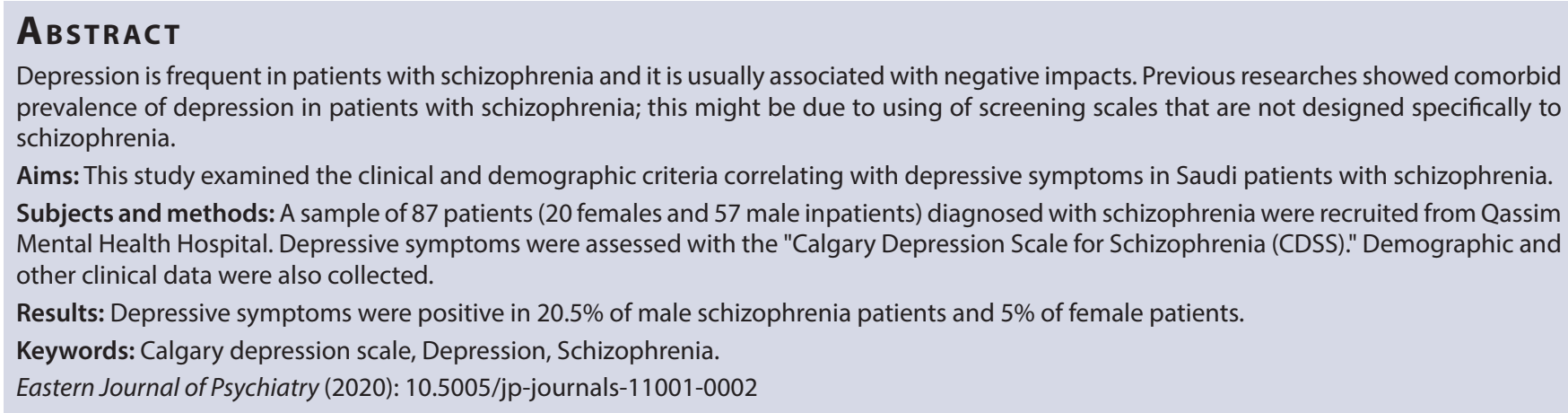

\section{INTRODUCTION}

Depressive disorder in schizophrenia is common. It has been reported to be around $40 \%$, whatever the severity of psychosis. ${ }^{1,2}$ Depression when it happens to patients with schizophrenic is linked to poorer outcomes. It has been found that patients with comorbid schizophrenia and depression were suggestively more likely to get more frequent relapses, to have more legal and safety problems (being violent, frequent arrests, victimization, and more suicidal behaviors), they also have larger substance-related problems, and they report poorer quality of life, cognitive functioning, family disharmony, and poorer medication adherence. ${ }^{3}$

Upthegrove et al. ${ }^{4}$ stated that "The Calgary Depression Scale (CDSS)" is extensively used to assess depression in subjects with schizophrenia. It stresses on the subjective symptoms of guilt, hopelessness, and suicidal ideation rather than agitation, anhedonia, and paranoid symptoms as seen in other depression rating scales.

Several mechanisms have been suggested for the development of depressive features in schizophrenic patients. Birchwood et al. ${ }^{5}$ suggest a discrepancy between three pathways: first, an intrinsic emotional disorder that is in line with the psychosis diathesis; second, the psychological reaction to this emotional disorder; and third, the end result of disturbed developmental pathways.

Avguštin ${ }^{6}$ mentioned several types of association of depression with schizophrenia: depression as a feature of prodromal stage: (1) Depressive symptoms are associated with the acute phase of the psychosis in majority of cases. Drug-naïve subjects show higher prevalence of symptoms. (2) Distress and depression can result from persistence of positive symptoms in the chronic phase of the illness. (3) Reactions to frustrations, a sense of loss or helplessness, or recognition of the psychotic symptoms or the psychological shortfalls can certainly present as or add to depression, especially when depression develops shortly after a stressful event or aggravation of schizophrenia. (4) It can be claimed that the upsurge in depression during the post-psychotic depression phase may be
'Department of Psychiatry, Qasim Mental Health Hospital, Saudi Arabia and Department of Psychiatry, North Area Armed Forces Hospital, Saudi Arabia

2,3,5-7 Department of Psychiatry, Qasim Mental Health Hospital, Saudi Arabia

${ }^{4}$ Department of Psychiatry, Qassim Rehabilitation Center for Addiction, Al Qassim, Saudi Arabia

${ }^{8}$ Department of Psychiatry, Mansoura University, Egypt and Department of Psychiatry, North Area Armed Forces Hospital, Saudi Arabia

${ }^{9}$ Department of Electronic Engineering, Faculty of Engineering, Mansoura University, Egypt

Corresponding Author: Nevin FW Zaki, Department of Psychiatry, Mansoura University, Egypt, Department of Psychiatry, North Area Armed Forces Hospital, Phone: +201283339789, e-mail: mernakero@mans.edu.eg; nevinfzaki@yahoo.com

How to cite this article: Al-Ruwais N, AlHarbi $\mathrm{Y}$, Abalkhail B, et al. Screening for Depression among Schizophrenia Patients: A Cross-sectional Study. East J Psychiatry 2020;23(1):15-20.

Source of support: Nil

Conflict of interest: None

an early sign of a further psychotic episode, because dysphoria is a known precursor of psychotic relapse.

Studies of depression in Arab and Saudi patients is scanty; hence, the importance of the current descriptive study. Thus, we aimed to study the prevalence of depression and its demographic and clinical correlates in a sample of inpatients with schizophrenia admitted at Qassim Mental Health Hospital.

\section{Subjects And Methods}

This is a cross-sectional observational study conducted between the period of January and May 2020.

IRB approval number: MS-1442.

(9)The Author(s). 2020 Open Access This article is distributed under the terms of the Creative Commons Attribution 4.0 International License (https://creativecommons. org/licenses/by-nc/4.0/), which permits unrestricted use, distribution, and non-commercial reproduction in any medium, provided you give appropriate credit to the original author(s) and the source, provide a link to the Creative Commons license, and indicate if changes were made. The Creative Commons Public Domain Dedication waiver (http://creativecommons.org/publicdomain/zero/1.0/) applies to the data made available in this article, unless otherwise stated. 
The study was conducted in Qassim Mental Health Hospital, the hospital is located in the central area of Saudi Arabia, specifically in Buraydah (the capital of Qassim region). It has a bed capacity of 250 , which serves a million plus population. All inpatients are above 18 years old. The diagnostic profile of the admitted patients are mainly schizophrenia and mood disorders. The hospital provides tertiary care for other psychiatric subspecialties including addiction, child/adolescent, and geriatric, among others.

We used the Arabic version of Calgary Depression Scale translated and validated by Hani et al. ${ }^{7}$ The scale was originally developed by Addington et al. ${ }^{8}$ "The CDSS is a nine-item structured interview." Originally an 11-item scale the CDSS was initially established from, and validated alongside the factor analysis, internal consistency, and face validity of the Hamilton Depression Rating Scale (HDRS), Beck Depression Inventory (BDI), and the Brief Psychiatric Rating Scale (BPRS). It has a high internal consistency: a $=0.76-0.86$. The current CDSS contains eight structured questions and a ninth observational item that depends on observation of the rater over the course of the interview. ${ }^{9}$ Current Items are constructed to measure: "(1) Depression; (2) Hopelessness; (3) Self-deprecation; (4) Guilty ideas; (5) Pathological guilt; (6) Morning depression; (7) Early wakening; (8) Suicidal ideation; and (9) Observed depression." Items are rated on a 4-point Likert type scale $(0$, absent; 1 , mild; 2 , moderate; 3 , severe), moored by descriptors. The scores of all nine items are summed to obtain the CDSS depression total score. A score higher than six has an $82 \%$ specificity and $85 \%$ sensitivity for predicting the presence of a major depressive episode.

\section{Results}

A total of 58 male and 20 female schizophrenic patients were recruited. Mean age was 50.7 years, and mean weight was $74.5 \mathrm{~kg}$. Mean income was 910 Saudi Riyal per month. Means and standard deviations of the sample criteria can be seen in Table 1.

There was a statistically significant difference between men and women on a number of sample criteria including marital status, type of carer, the carer attitude toward the patient, type of accommodation the patient lives in, the source of social support, and the history of legal problems. Other clinical factors showed no gender differences. This information is summarized in Table 2.

In Table 3, the variables which impacted the most, the Calgary Depression Score of the recruited sample are shown. Other factors which had no impact are not shown in the table. It can be noticed that gender, positive family history of psychosis, positive family history of bipolar disorder, the social support of the patient, previous suicide attempts, the legal history, and history of comorbid systemic diseases are all factors that impacted the depressive features in the recruited sample.

\section{Discussion}

In this study, we aimed at studying the prevalence of depression among patients with schizophrenia and its correlated demographic and clinical variables. Since depressive features might simulate the negative symptoms of schizophrenia, we used the CDSS due to its high specificity and sensitivity for detecting symptoms of depression in patients with schizophrenia.

In this study, $20 \%$ of males and $5 \%$ of females had depressive features. This percentage is a bit lower than that reported by Hoertel et al. ${ }^{10}$ who found that $78.1 \%$ of their sample had either subsyndromal (30.6\%) or syndromal (47.5\%) depressive symptoms. Calgary scores were independently associated with positive and negative symptoms, lower quality of life, non-late-onset psychosis, benzodiazepine use, and urbanicity.

In the current study previous suicide attempts had an impact on the Calgary scores. This was also reported by Zhou et al. ${ }^{11}$ who found that lifetime suicide is common among hospitalized patients with schizophrenia living in agricultural areas of China.

Furthermore, animal model of Zhong et al. ${ }^{12}$ demonstrated that the activity and functioning of critical neural areas in the prefrontal cortex is more severely affected in schizophrenia with depression mouse models than in mouse models of schizophrenia or depression alone. More importantly, it was found that combined treatment using antipsychotics and antidepressants cannot fully undo either the behavioral or the neural activity damages. These data suggest that schizophrenia complicated by depression may be an unrecognized mental disorder object that is separate from other mental disorders.

In this study CDSS was higher in those who did not go out on passes, those with positive family history of bipolar and those with more comorbid systemic illness. These results are similar to El-Bahy and Mohamed ${ }^{13}$ which suggest that patients with schizophrenia who have not been diagnosed with depression frequently have $30 \%$ clinical symptoms of depression. In addition, Subodh and Grover ${ }^{14}$ found that one-fifth of their patients with schizophrenia had noteworthy depression that was associated with a higher level of disability in interpersonal activities, and poorer quality of life compared to schizophrenia patients without significant depression. Furthermore, Pradeep and Sankaran ${ }^{15}$ stated that depressive symptoms in schizophrenia might lead to bigger number of hospitalization and high mortality rate including suicide.

Our study is comparable to the study in Ethiopia by Fanta et al. $^{2}$ who found the prevalence of depression among people

Table 1: Means and standard deviations of sample criteria

\begin{tabular}{llll}
\hline Variable & Min & Max & Mean ( \pm SD) \\
\hline Age & 19 & 87 & $50.7(15.5)$ \\
Number of kids & 0 & 8 & $0.7(1.6)$ \\
Number of pass days & 0 & 30 & $1.9(4.7)$ \\
Number of admissions & 1 & 16 & $2.9(3)$ \\
Weight in kg & 42 & 130 & $74.5(16)$ \\
Height in cm & 140 & 189 & $165.4(10)$ \\
BMl & 18 & 42 & $27.2(5.3)$ \\
Income in Saudi Riyal & 0 & 10000 & $910.7(1766.9)$ \\
Total CDSS score & 0 & 17 & $4(4.5)$ \\
\hline
\end{tabular}


Table 2: Demographic and clinical criteria of the recruited subjects

\begin{tabular}{|c|c|c|c|c|}
\hline Variable & Males N(\%) & Females N(\%) & $\chi^{2}$ & $p$ \\
\hline \multicolumn{5}{|l|}{ Marital status } \\
\hline Single & $48(61.4)$ & $11(14.1)$ & 15.5 & 0.004 \\
\hline Maried & $5(6.4)$ & 0 & & \\
\hline Widowed & 0 & $1(1.3)$ & & \\
\hline Divorced & $5(6.4)$ & $8(10.3)$ & & \\
\hline \multicolumn{5}{|l|}{ Menopause } \\
\hline Not applicable & $58(74.4)$ & 0 & 41 & 0.0001 \\
\hline Yes & - & $9(11.5)$ & & \\
\hline No & - & $11(14.1)$ & & \\
\hline \multicolumn{5}{|l|}{ Obesity degree according to $\mathrm{BMI}$} \\
\hline Underweight & $1(1.3)$ & $1(1.3)$ & 6.6 & 0.24 \\
\hline Normal & $20(25.6)$ & $5(6.4)$ & & \\
\hline Overweight & $25(32.1)$ & $5(6.4)$ & & \\
\hline Obese class I & $8(10.3)$ & $6(7.7)$ & & \\
\hline Obese class II & $3(3.8)$ & $3(3.8)$ & & \\
\hline Obese class III & $1(1.3)$ & 0 & & \\
\hline \multicolumn{5}{|l|}{ Involved in rehabilitation } \\
\hline Yes & $30(38.5)$ & $7(9)$ & 1.8 & 0.4 \\
\hline No & $28(35.9)$ & 13(16.7) & & \\
\hline \multicolumn{5}{|l|}{ Carer } \\
\hline Parents & $16(20.5)$ & $4(5.1)$ & 19.4 & 0.004 \\
\hline Siblings & $1(1.3)$ & 0 & & \\
\hline Wife & $2(2.6)$ & 0 & & \\
\hline Family & $31(39.7)$ & $5(6.4)$ & & \\
\hline Others & 0 & $3(3)$, & & \\
\hline No host & 7(9) & $8(10.3)$ & & \\
\hline \multicolumn{5}{|c|}{ Carer attitude toward the patients } \\
\hline Very caring & $6(7.7)$ & $03(3.8)$ & 13.5 & 0.009 \\
\hline Caring & $28(35.9)$ & $12(15.4)$ & & \\
\hline Not caring & 19(24.4) & $5(6.4)$ & & \\
\hline Rejecting & $5(6.4)$ & 0 & & \\
\hline \multicolumn{5}{|l|}{ Out on passes } \\
\hline Yes & $27(34.6)$ & $7(9)$ & 1 & 0.6 \\
\hline No & $31(39.7)$ & 13(16.7) & & \\
\hline \multicolumn{5}{|l|}{ Living with } \\
\hline Alone & $7(9)$ & $5(6.4)$ & 3.8 & 0.4 \\
\hline Family & $46(59)$ & 13(16.7) & & \\
\hline Servant & $1(1.3)$ & 0 & & \\
\hline Others & $4(5.1)$ & $2(2.6)$ & & \\
\hline \multicolumn{5}{|l|}{ Type of accommodation } \\
\hline Owned & $40(51.3)$ & $9(11.6)$ & 17 & 0.002 \\
\hline Rented & $12(15.4)$ & $2(2.6)$ & & \\
\hline Accommodated at the hospital & $1(1.3)$ & 0 & & \\
\hline Homeless & $5(6.4)$ & $9(11.5)$ & & \\
\hline
\end{tabular}


Table 2: (Contd...)

\begin{tabular}{|c|c|c|c|c|}
\hline Variable & Males N(\%) & Females N(\%) & $\chi^{2}$ & $p$ \\
\hline \multicolumn{5}{|c|}{ Family history of psychosis } \\
\hline Negative & $30(38.5)$ & $11(14.1)$ & 3 & 0.2 \\
\hline Positive & $28(35.9)$ & $9(11.6)$ & & \\
\hline \multicolumn{5}{|c|}{ Family history of bipolar disorder } \\
\hline Negative & $41(52.6)$ & $17(21.8)$ & 1.7 & 0.4 \\
\hline Positive & $17(21.6)$ & $3(3.8)$ & & \\
\hline \multicolumn{5}{|c|}{ Source of social support } \\
\hline Family & $27(34.7)$ & 0 & 38.6 & 0.0001 \\
\hline Neighbors & $2(2.6)$ & 0 & & \\
\hline Governmental & $12(15.4)$ & $20(25.5)$ & & \\
\hline Society/charity & $2(2.6)$ & 0 & & \\
\hline \multicolumn{5}{|c|}{ Number of suicidal attempts } \\
\hline None & $50(64.1)$ & $20(25.6)$ & 3 & 0.38 \\
\hline Once & $6(7.7)$ & 0 & & \\
\hline Twice & $1(1.3)$ & 0 & & \\
\hline Four times & $1(1.3)$ & 0 & & \\
\hline \multicolumn{5}{|c|}{ History of legal problems } \\
\hline None & $45(57.7)$ & $20(25.6)$ & 5.3 & 0.014 \\
\hline Positive & 13(16.7) & 0 & & \\
\hline
\end{tabular}

Table 3: CDSS among the recruited subjects

\begin{tabular}{|c|c|c|c|}
\hline \multirow[t]{2}{*}{ Variable } & \multirow{2}{*}{$\begin{array}{l}\text { Calgary Schizophrenia Depression Scale } \\
\text { No depression N\% }\end{array}$} & \multicolumn{2}{|r|}{$p$} \\
\hline & & Positive depression & N\% \\
\hline \multicolumn{4}{|l|}{ Gender } \\
\hline Male & $42(53.8)$ & $16(20.5)$ & 0.32 \\
\hline Female & $16(20.5)$ & $4(5.1)$ & \\
\hline \multicolumn{4}{|l|}{ Out on passes } \\
\hline Yes & $37(47.4)$ & $7(9)$ & 0.029 \\
\hline No & $21(26.9)$ & $13(16.7)$ & \\
\hline \multicolumn{4}{|c|}{ Family history of psychosis } \\
\hline Yes & $37(47.4)$ & $4(5.1)$ & 0.002 \\
\hline No & $21(26.9)$ & $16(20.5)$ & \\
\hline \multicolumn{4}{|c|}{ Family history of bipolar } \\
\hline Yes & $7(9)$ & $13(16.7)$ & 0.0001 \\
\hline No & $51(65.4)$ & $7(9)$ & \\
\hline \multicolumn{4}{|c|}{ Carer attitude toward the patient } \\
\hline Very caring & $5(6.4)$ & $1(1.3)$ & 0.034 \\
\hline Caring & $17(21.8)$ & $14(17.9)$ & \\
\hline Not caring & 27)(34.6) & $4(5.1)$ & \\
\hline Rejecting & $9(11.4)$ & $1(1.3)$ & \\
\hline \multicolumn{4}{|c|}{ Source of social support } \\
\hline Family & $13(16.7)$ & $12(15.4)$ & 0.013 \\
\hline Neighbors & $1(1.3)$ & $1(1.3)$ & \\
\hline Governmental & $27(34.4)$ & $7(9)$ & \\
\hline \multirow[t]{2}{*}{ Society/charity } & $2(2.6)$ & 0 & \\
\hline & & & (Contd...) \\
\hline Eastern J & e 1 (January-June 2020) & & 20 \\
\hline
\end{tabular}


Table 3: (Contd...)

\begin{tabular}{lll}
\hline Variable & Calgary Schizophrenia Depression Scale & $p$ \\
\hline Lacking & No depression N\% & Positive depression \\
History of suicide attempts & 0 & $15(19.2)$ \\
Yes & & $14(17.9)$ \\
No & $55(70.5)$ & $6(7.7)$ \\
Legal history & $3(3.8)$ & 9.007 \\
Yes & & $9(11.5)$ \\
No & $4(5.1)$ & $11(14.1)$ \\
Comorbid systemic disease & $54(69.2)$ & $14(21.8)$ \\
Yes & & $3(3.8)$ \\
No & $18(23.1)$ & 0.0001 \\
\hline
\end{tabular}

with schizophrenia was found to be $18.0 \%$ multivariable regression analysis exposed that current substance use, suicide attempt, duration of illness between 6 and 10 years and poor quality of life were found to be the factors associated with depression among people with schizophrenia.

And also, the study of Balci et al. ${ }^{16}$ found prevalence of some medical diseases like hypertension, chronic obstructive pulmonary disease, and coronary artery disease, was more than twice bigger in depressed schizophrenic patients. In a study by Sari et al. ${ }^{17}$ found depression rate in schizophrenia is found as $42.5 \%$. Depression was related to low socioeconomic status.

\section{Study Strength and Limitations}

The current survey had several strengths including (1) to our knowledge this is the first cross sectional study to screen for depressive features in Saudi schizophrenic subjects. (2) The main outcome of interest (depression) was measured using standardized and validated instrument (CSSD) specifically designed to identify depression in schizophrenia. (3) Furthermore, most patients were admitted for long time and their functional impairment was evident more than the acutely affected patients making them a good target of the study. Limitations: (1) The cross-sectional nature of the study indicates some bias in the relationship between the different factors and depression. (2) We didn't quantify the severity of negative symptoms using structured scales thus the findings may not differentiate whether the depressive symptoms are associated with the negative symptoms of schizophrenia or they are purely symptoms of depression. (3) Finally the relatively small sample size makes further studies recruiting larger samples of patients a needed research target.

\section{Conclusion}

Clinicians should put in mind that patients negative symptoms of schizophrenia might affect the ratings of depression and obscure its clinical presentation, and should be aware that depressive symptoms in these patients might lead to functional limitations, and worsen the prognosis. Examining related sociodemographic factors can aid in determining depression in all the phases of schizophrenia.

\section{Author Contribution}

Nevin: Manuscript preparation, manuscript editing and manuscript review.
Nabil: Concept, design, definition of intellectual content, literature search, clinical studies, data acquisition.

John: Data analysis, statistical analysis, manuscript preparation.

The rest of authors: Concept design and data acquisition.

\section{ACKNOWLedgments}

Authors would like to thank all the participating patients and their families.

Additionally, we would like to thank all the staff members of Qassim Mental Health Hospital for their logistic help. Furthermore, our deep gratitude to Mrs. Janey John, the research Unit Secretary, for her sincere help.

\section{References}

1. Conley RR, et al. The burden of depressive symptoms in the long-term treatment of patients with schizophrenia. Schizophr Res 2007;90(1-3):186-197. DOI: 10.1016/j.schres.2006.09.027

2. Fanta T, Bekele D, Ayano G. The prevalence and associated factors of depression among patients with schizophrenia in Addis Ababa, Ethiopia, cross-sectional study. BMC Psychiatr 2020;20(1):1-6. DOI: 10.1186/s12888-019-2419-6

3. McGinty J, Upthegrove R. Depressive symptoms during first episode psychosis and functional outcome: a systematic review and meta-analysis. Schizophr Res 2020;218:14-27. DOI: 10.1016/j. schres.2019.12.011

4. Upthegrove R, Marwaha S, Birchwood M. Depression and schizophrenia: cause, consequence, or trans-diagnostic issue? Schizophr Bull 2017;43(2):240-244. DOI: 10.1093/schbul/sbw097

5. Birchwood M, lqbal Z, Chadwick $P$, et al. Cognitive approach to depression and suicidal thinking in psychosis: I. Ontogeny of post-psychotic depression. Br J Psychiatr 2000;177(6):516-521. DOI: 10.1192/bjp.177.6.516

6. Avguštin B. Depression in schizophrenia-literature overview. Psychiatr Danub 2009;21(1):93-97. DOI: 10.1007/s00115-001-1222-y

7. Hani $Y$, Ghuloum S, Mahfoud Z, et al. Validation of the Arabic version of Calgary depression scale for schizophrenia. PLoS One 2016;11(9) e0162304. DOI: 10.1371/journal.pone.0162304

8. Addington D, Addington J, Maticka-Tyndale E. Assessing depression in schizophrenia: the Calgary Depression Scale. Br J Psychiatr Suppl 1993;163(S22):39-44. DOI: 10.1192/S0007125000292581

9. Kim S-W, Kim S-J, Yoon B-H, et al. Diagnostic validity of assessment scales for depression in patients with schizophrenia. Psychiatr Res 2006;144(1):57-63. DOI: 10.1016/j.psychres.2005.10.002 
10. Hoertel N, Jaffré C, de Raykeer RP, et al. Subsyndromal and syndromal depressive symptoms among older adults with schizophrenia spectrum disorder: prevalence and associated factors in a multicenter study. J Affect Disord 2019;251:60-70. DOI: 10.1016/j.jad.2019.03.007

11. Zhou C, Kong D, Zhu X, et al. Rethinking schizophrenia and depression comorbidity as one psychiatric disorder entity: evidence from mouse model. Front Neurosci 2020;14:115. DOI: 10.3389/fnins.2020.00115

12. Zhong Y, Xia L, Zhao T-T, et al. The prevalence of suicide attempts and independent demographic and clinical correlates among chronic schizophrenia patients in agricultural areas of China. Psychiatr Q 2019;90(4)683-691. DOI: 10.1007/s11126-019-09644-1

13. El-Bahy M, Mohamed W. Prevalence of depression in schizophrenic patients evaluated by the Calgary Depression Scale in Shebin El-Kom, Menoufiya. Middle East Curr Psychiatr 2013;20(4):191-196. DOI: 10.1097/01.XME.0000433781.14841.77
14. Subodh BN, Grover P. Depression in schizophrenia: prevalence and its impact on quality of life, disability, and functioning. Asian J Psychiatr 2020;54:102425. DOI: 10.1016/j.ajp.2020.102425

15. Pradeep M, Sankaran A. Frequency and characterization of depression in schizophrenia. Ann Indian Psychiatr 2020;4(1):56. DOI: 10.4103/aip.aip_59_19

16. Balci G, Gajić Z, Ivetić O, et al. Factors associated with depression in patients with schizophrenia. Acta Clin Croat 2016;6(2):54. DOI: 10.20471/acc.2020.59.04.06

17. Sari SP, Dwidiyanti M, Wijayanti DY, et al. Prevalence, demographic, clinical features and its association of comorbid depressive symptoms in patients with schizophrenia. Schizophr Res 2017;21(2). DOI: 10.1016/j.schres.2017.06.029 